\title{
Ionic Mechanism of Long-Lasting Discharges of Action Potentials Triggered by Membrane Hyperpolarization in the Medial Lateral Habenula
}

\author{
Su-youne Chang and Uhnoh Kim \\ Department of Biomedical Sciences and Interdepartmental Neuroscience Program, College of Veterinary Medicine, Iowa State University, Ames, Iowa \\ $50011-1250$
}

\begin{abstract}
The activation of inhibitory synapses typically suppresses the generation of action potentials by hyperpolarizing the membrane of postsynaptic cells. In contrast to such conventional action of inhibitory synapses, we report here the ionic mechanism through which hyperpolarizing synapses trigger long-lasting discharges of action potentials that persist up to several tens of seconds. By using extracellular and intracellular recordings in slice preparations, we demonstrate that the activation of synaptic input from the limbic forebrain generates transient hyperpolarizing postsynaptic potentials in neurons of the medial part of the lateral habenular nucleus of the epithalamus. The synaptic hyperpolarization then sets off the coordinated activation of a distinct set of membrane ion channels and intracellular $\mathrm{Ca}^{2+}$ mobilization by internal stores. The activation of these cellular events in distinct temporal order drives a persistent depolarization of habenular cells and promotes long-lasting discharges of tonic action potentials. The cells in the medial division of the lateral habenula project to dopamine and serotonin cells in the midbrain. We suggest that these habenular cells, by generating persistent action potentials in response to a transient increase in the activity of the limbic forebrain, may contribute to the regulation of the serotonergic and dopaminergic activity in the brain.
\end{abstract}

Key words: habenula; thalamus; depolarizing afterpotential; low-threshold and high-threshold $\mathrm{Ca}^{2+}$ currents; CAN currents; intracellular $\mathrm{Ca}^{2+}$ mobilization; synaptic hyperpolarization

\section{Introduction}

The habenular complex of the epithalamus is located on the floor of the third ventricle in the posterior medial aspect of the dorsal thalamus. Previous anatomical studies suggested that the habenular complex comprises tripartite, partially segregated channels of information flow from the forebrain to various midbrain structures (Herkenham and Nauta, 1977, 1979; Sutherland, 1982; Ellison 1994; Hermann et al., 1997). For instance, in the rat, the medial nucleus of the habenula receives main input from the septum and, in turn, projects to the interpeduncular nucleus. The lateral habenular nucleus is further subdivided into the medial and lateral parts. The medial part of the lateral habenula receives input primarily from the limbic regions of the forebrain and, in lesser degree, from the globus pallidus. This medial lateral habenula gives rise to projections primarily to the dorsal raphe nucleus. In contrast, the lateral part of the lateral habenula receives input mainly from the globus pallidus. The major targets of projections from the lateral part of the lateral habenula are the midbrain reticular formation and tegmentum.

Received July 14, 2003; revised Dec. 22, 2003; accepted Dec. 23, 2003.

This work was supported by research grant from the Whitehall Foundation.

Correspondence should be addressed to Dr. Uhnoh Kim, Department of Biomedical Sciences, Interdepartmental Neuroscience Program, College of Veterinary Medicine, lowa State University, Ames, IA 50011-1250. E-mail: ukim@iastate.edu.

DOI:10.1523/JNEUROSCI.4891-03.2004

Copyright $\odot 2004$ Society for Neuroscience $\quad 0270-6474 / 04 / 242172-10 \$ 15.00 / 0$
In partial agreement with the tripartite organization of the habenula, previous in vitro electrophysiological studies demonstrated a dichotomy of spontaneous activity in the habenula. For example, the neurons in the medial habenular nucleus spontaneously generate tonic firing of action potentials (McCormick and Prince, 1987), whereas neurons in the lateral habenular nucleus produce spontaneous burst oscillations (Wilcox et al., 1988). These bursts of action potentials in the lateral habenular nucleus are mediated by the activation of low-threshold $\mathrm{Ca}^{2+}$ current (Wilcox et al., 1988; Huguenard et al., 1993). It has yet to be shown whether the medial and lateral parts of the lateral habenula exhibit any difference in their intrinsic electrophysiological properties and patterns of action potential generation.

Previous in vivo electrophysiological studies implicated that the habenula may play an important role in regulating serotonin activity in the brain. For instance, a change in habenular activity in response to either local electrical stimulation or a local injection of substance $P$ antagonist resulted in alterations in the activity of serotonin cells in the dorsal raphe nucleus (Matsuda and Eaton, 1990; Ferraro et al., 1996; Conley et al., 2002). Because the projections to the dorsal raphe nucleus arise mainly from the medial part of the lateral habenula, and this habenular area receives its input mainly from the limbic regions of the forebrain (Herkenham and Nauta, 1977, 1979), it is probable that the medial part of the lateral habenula signals the activity change in the limbic forebrain to the dorsal raphe nucleus for regulating serotonin cell activity. 
In the present study, by use of whole-cell patch recordings from the brain slice preparation, we demonstrate that the major population of neurons in the medial part of the lateral habenula possess distinct intrinsic properties that enable a long-lasting discharge of action potentials for duration of several tens of seconds in response to synaptic hyperpolarization. This peculiar synaptic activation of action potentials was encountered almost exclusively in the medial part of the lateral habenula, thus supporting the tripartite organization of the habenula. The long-lasting activation of action potentials is mediated by the activation of $\mathrm{Ca}^{2+}$. activated nonselective cationic (CAN) current. Here, we present the cellular mechanisms through which synaptic hyperpolarization is linked to the activation of CAN current for the long-lasting discharge of action potentials.

\section{Materials and Methods}

Slice preparation. Habenular brain slices were obtained from 18- to 23 d-old Sprague Dawley rats. All experimental procedures were approved by the Animal Care and Use Committee at Iowa State University and in accordance with the National Institutes of Health Guide for the Use and Care of Laboratory Animals. Animals were deeply anesthetized with an intraperitoneal injection of a lethal dose of sodium barbiturate. For most experiments, $400-\mu \mathrm{m}$-thick coronal brain slices were generated from the habenula of the epithalamus. For the experiments that required electrical stimulation of the stria medullaris, sagittal habenular slices were generated. The slices were preincubated before an experiment for at least $2 \mathrm{hr}$ at room temperature in artificial CSF (ACSF) containing (in mM): 125 $\mathrm{NaCl}, 2.5 \mathrm{KCl}, 26 \mathrm{NaHCO}_{3}, 1.25 \mathrm{NaHPO}_{4}, 1.2 \mathrm{MgSO}_{4}, 2 \mathrm{CaCl}_{2}$, and 15 dextrose, saturated with $95 \% \mathrm{O}_{2}$ and $5 \% \mathrm{CO}_{2}, \mathrm{pH}$ 7.4. For intracellular recordings, slices were transferred to a submerged type recording chamber that was fixed to the stage of the BX50WI microscope (Olympus, Tokyo, Japan) and were superfused at $3 \mathrm{ml} / \mathrm{min}$ with ACSF. For extracellular recordings, slices were transferred to an interface type recording chamber and superfused with ACSF at $0.5-1 \mathrm{ml} / \mathrm{min}$. All experiments were conducted at $32-34^{\circ} \mathrm{C}$.

Electrophysiological recordings. Whole-cell intracellular recordings were performed under visual guidance using differential interference contrast optics of the Olympus BX50WI microscope and Nubicon-tube video camera (Dage-MTI, MI City, IN). Patch pipettes were pulled from borosilicate glass tubing (outer diameter $1.5 \mathrm{~mm}$, inner diameter 0.84 $\mathrm{mm}$ ) and filled with internal solution composed of (in $\mathrm{mM}$ ): 125 K-gluconate, $10 \mathrm{KCl}, 10$ HEPES, 1 EGTA, $2 \mathrm{MgCl}_{2}, 0.1 \mathrm{CaCl}_{2}, 15 \mathrm{Tris}_{2}$ phosphocreatine, $4 \mathrm{Na}_{2}$-ATP, and $0.3 \mathrm{GTP}, \mathrm{pH} 7.2,280 \mathrm{mOsm} / \mathrm{kg}$. Typical electrode resistance was 3-5 M $\Omega$, with access resistance in the range of 5-10 $\mathrm{M} \Omega$. Serial resistance compensation $>40 \%$ was routinely used. The measured membrane potentials were corrected for the junction potential of $-10 \mathrm{mV}$. Cells with a series resistance of $>30 \mathrm{M} \Omega$ were discarded from further analysis. Whole-cell recordings were made using an Axoclamp 2B amplifier (Axon Instruments, Foster City, CA). For extracellular recordings, patch pipettes filled with ACSF (3-5 M 2 ) were used to record single-unit extracellular activity. Extracellular signals were recorded with an Xcell-3 amplifier (FHC, Bowdoinham, ME), sampled at $20 \mathrm{kHz}$, and analyzed using pClamp8 software.

To stimulate synaptic input from the limbic forebrain to the habenula, a bipolar stimulating electrode was placed on the stria medullaris $300-$ $500 \mu \mathrm{m}$ away from the cells that were recorded with either extracellular or intracellular electrodes. Electrical stimuli consisted of current pulses $100 \mu \mathrm{sec}$ in duration and ranged from 50 to $150 \mu \mathrm{A}$ in current amplitude. The stimuli were delivered through stimulus isolation unit (WPI, Sarasota, FL).

Data analysis. Data were collected using pClamp8 software via an analog-to-digital converter (Digidata 1320; Axon Instruments). The data were presented as mean $\pm \mathrm{SD}$. Statistical comparisons were made with Student's paired $t$ test; the corresponding $p$ values are given in the text. $p$ values $<0.05$ were considered statistically significant.

Drugs. For bath application of flufenamic acid, thapsigargin, nifedipine, and dantrolene (Sigma, St. Louis, MO), they were initially dissolved
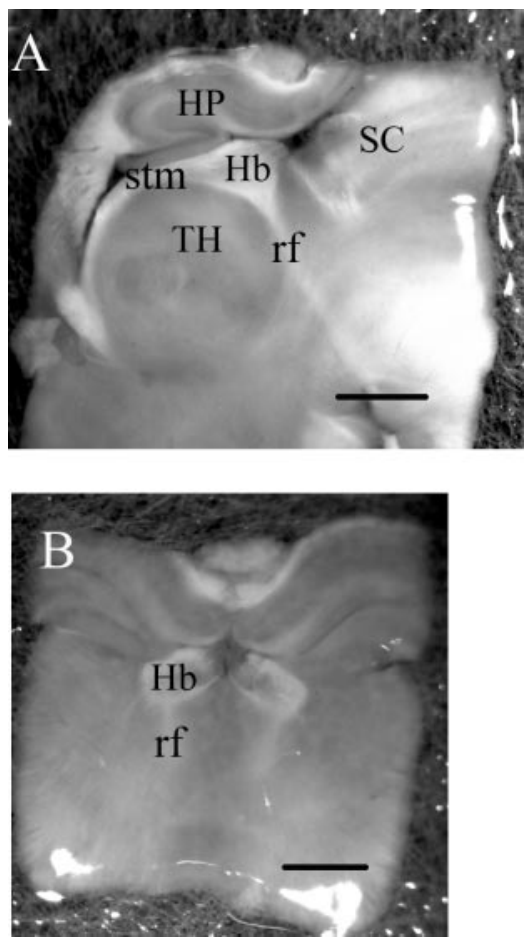

Figure 1. Photomicrographs of a sagittal $(A)$ and a frontal habenular slice $(B)$. The habenula $(\mathrm{Hb})$ receives major input from the striatum and limbic forebrain through the stria medullaris (stm). The efferents from the habenula travel via the fascicles retroflexus (rf) to various nuclei of the midbrain. Scale bars, $1 \mathrm{~mm}$. HP, Hippocampus; TH, thalamus; SC, superior colliculus.

in DMSO and then added to ACSF. The final concentration of DMSO was $0.01-0.05 \%$. The bath infusion of $0.05 \%$ DMSO alone in ACSF did not alter the electrical property of habenular cells. For bath application of tetrodotoxin (TTX) and apamin (Sigma), they were dissolved in ACSF. In the presence of TTX, bath infusion of thapsigargin depolarized the resting membrane potential by $1-4 \mathrm{mV}$, whereas dantrolene hyperpolarized the membrane by $2-4 \mathrm{mV}$. In those cases, we adjusted the membrane potential to the resting level before drug infusion by injecting steady current before further proceeding with experiments. Bath infusion of apamin, FFA, and nifedipine produced little change in the resting membrane potential.

\section{Results}

The electrical stimulation of the stria medullaris produces hyperpolarizing postsynaptic potentials that induce longlasting, intense discharges of action potentials

Along the way of projections, the axon fibers arising from various areas of the forebrain join together and form fiber bundles that travel in the stria medullaris to reach the habenula. The connection between the stria medullaris and the habenula was well preserved in sagittal habenular slices (Fig. 1).

In sagittal habenular slices, electrical stimulation of the stria medullaris produced complex patterns of responses in the cells located in the medial part of the lateral habenular nucleus. The representative examples are shown in Figure 2. Our extracellular recordings from the lateral habenular cells that are illustrated in Figure 2, $A a$ and $A b$, showed that they generated action potentials spontaneously at frequencies of $\sim 9$ and $11 \mathrm{~Hz}$, respectively. In these cells, electrical stimulation of the stria medullaris resulted in a brief inhibition of spontaneous activity for $\sim 0.7-1 \mathrm{sec}$. In Figure $2 A a$, the inhibitory period was followed by increases in firing up to $\sim 17 \mathrm{~Hz}$ for the initial 3-4 sec. Then, the firing rate declined gradually over the next $4-5 \mathrm{sec}$ and returned to the spontaneous level. In another cell shown in Figure $2 A b$, the inhibitory period 

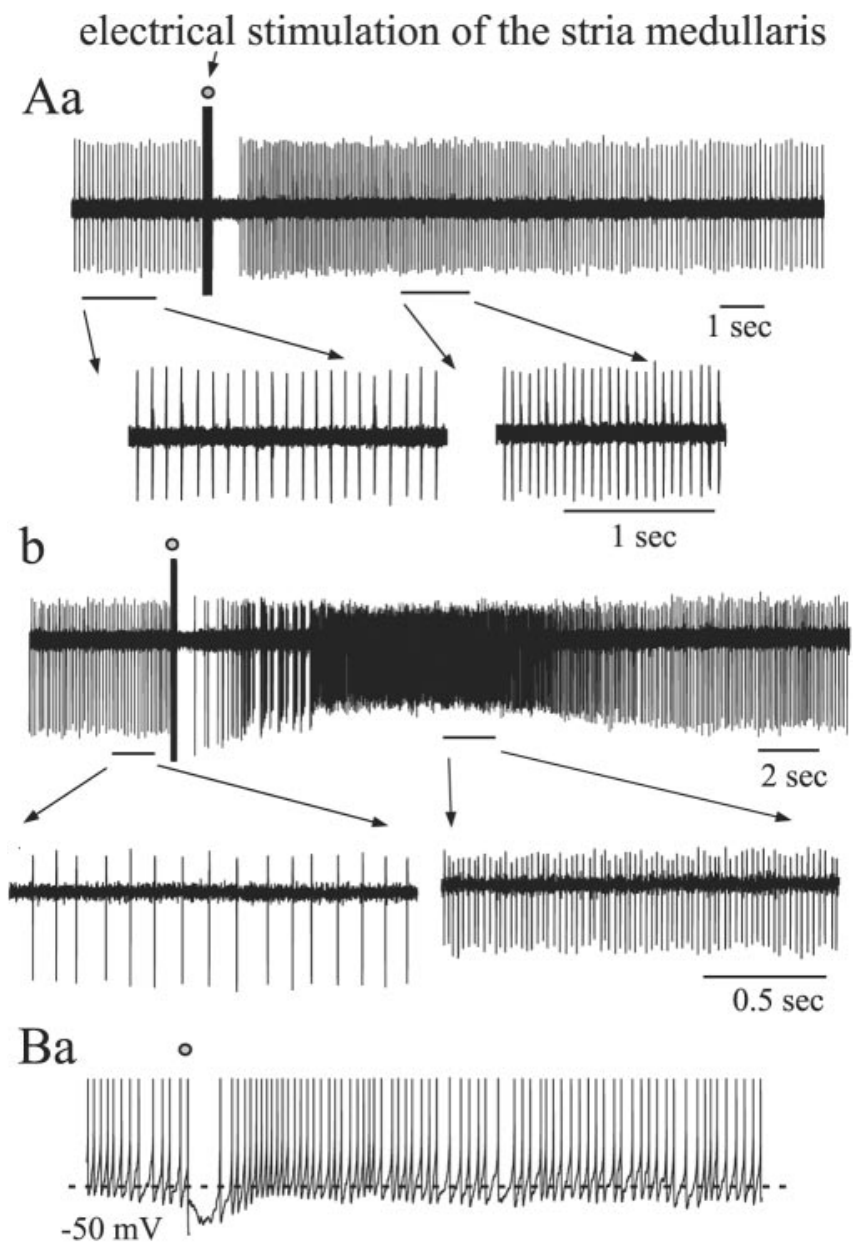

$\mathrm{b}$

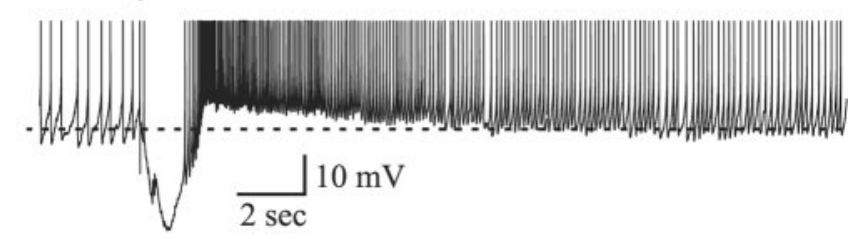

Figure 2. Electrical stimulation of the stria medullaris produces a brief inhibition of habenular activity that is followed by persistent increases in firing. $A a, A b$, Extracellular recordings from two different habenular cells. A train of 10 electrical stimuli at $100 \mathrm{~Hz}$ was delivered to the stria medullaris. The stimulation resulted in a brief inhibition of spontaneous activity for $\sim 700 \mathrm{msec}$ to $1 \mathrm{sec}$. The inhibition was followed by marked increases in firing. $B a$, Whole-cell patch intracellular recording from a lateral habenular cell. A single electrical stimulation to the stria medullaris $(100 \mu \mathrm{A})$ generated a hyperpolarizing postsynaptic potential of $\sim 10 \mathrm{mV}$ in amplitude and 1 sec in duration. This synaptic hyperpolarization transiently inhibited spontaneous firing. $B b$, The increase in the amplitude of electrical stimulation to $150 \mu \mathrm{A}$ increased the size of the hyperpolarizing synaptic potential to $25-30 \mathrm{mV}$. This synaptic hyperpolarization was followed by burst and tonic increases in firing. The increases in tonic firing lasted for $\sim 40 \mathrm{sec}$. Action potentials are truncated in $B a$ and $B b$.

was followed first by three or four cycles of brief bursts and then by an increase in tonic firing up to $40-50 \mathrm{~Hz}$. The increase in tonic firing lasted for $14-18 \mathrm{sec}$ before the discharge rate returned to the spontaneous level.

The cells that exhibited the transient inhibition of spontaneous activity and the ensuing increase in tonic firing in response to electrical stimulation of the stria medullaris were most concentrated in the medial part of the lateral habenular nucleus. In this area, all tonically active cells recorded with extracellular elec- trodes showed a similar change in firing as was shown above in response to electrical stimulation of the stria medullaris $(n=6$ cells). In those six cells, the increase in tonic firing ensuing the transient inhibition persisted 7-26 sec (average $15.8 \pm 6.3 \mathrm{sec}$ ). Therefore, all our intracellular recordings shown below in this study were conducted in the medial part of the lateral habenula.

Our whole-cell intracellular recordings revealed that the brief inhibition of spontaneous activity in response to electrical stimulation of the stria medullaris results from the activation of hyperpolarizing postsynaptic potentials ( $n=9$ cells) (Fig. $2 \mathrm{~B}$ ). The size of these hyperpolarizing synaptic potentials grew as the current amplitude of electrical stimulation was increased. The decay of large size hyperpolarizing postsynaptic potentials led to the rebound generation of a brief burst of action potentials that was followed by persistent, tonic increases in firing (Fig. $2 \mathrm{Bb}$ ). This change in firing was consistent with that demonstrated above with extracellular electrodes in Figure $2 \mathrm{~A}$.

The cells in the medial part of the lateral habenula generate long-lasting, intense discharges of action potentials in response to the injection of a brief hyperpolarizing current pulse

Based on the pattern of spontaneous activity at rest, we classified cells in the medial part of the lateral habenular nucleus into three groups. The first group of cells exhibited spontaneous, tonic firing of action potentials in the frequency range of $1-20 \mathrm{~Hz}$ (Fig. $3 \mathrm{Aa}$ ) ( $n=69$ of total 132 cells). The average discharge rate was $5.7 \pm 2.6 \mathrm{~Hz}$. This pattern of spontaneous firing in the slice preparation is consistent with that of the habenular activity recorded in vivo from the cat with extracellular electrodes in a previous study (Meier and Herrling, 1993). To measure cell input resistance, we hyperpolarized the cells just below the threshold for action potentials by passing a steady negative current and superimposed a brief hyperpolarizing current pulse (100 msec, $10 \mathrm{pA})$. The average input resistance was $1070 \pm 382 \mathrm{M} \Omega(n=14$ cells). In contrast, cells of the second group were silent at rest (Fig. $3 A b)$ ( $n=31$ out of 132 cells). The resting membrane potentials of these cells $(-59 \pm 4 \mathrm{mV}$ ) were negative to the threshold for action potentials $(-52 \pm 1 \mathrm{mV})$ that was estimated as the onset of the regenerative phase of action potentials. The last group of cells generated spontaneous oscillations of burst discharges (Fig. 3Ac) ( $n=32$ of 132 cells). It is noteworthy that a subpopulation of cells in the first group altered the mode of spontaneous firing from tonic to burst oscillations when the membrane potential was hyperpolarized with the injection of steady negative current (Fig. $3 B)(n=7$ cells). Input resistances of cells in the three groups were not significantly different.

A common characteristic of cells of the first and second groups in the medial part of the lateral habenula is that they generate prolonged, intense discharges of burst and tonic mixtures of action potentials in response to a brief hyperpolarizing current pulse. A representative example is shown in Figure 4. In this cell, the injection of a 100-msec-long hyperpolarizing current pulse resulted in a dramatic rebound generation of action potentials (Fig. $4 A$ ). At the break of current pulse, it generated a burst of four or five high-frequency action potentials at $80-90 \mathrm{~Hz}$. This burst was followed by a tonic series of action potentials that continued, albeit gradually declining in discharge rate, over the next 15-20 sec. In a total of 40 cells analyzed, the duration of tonic action potential generation in response to a $100 \mathrm{msec}$ hyperpolarizing current pulse ranged from 3 to $39 \mathrm{sec}$ (average $14.8 \pm 8.5$ $\mathrm{sec})$. In these cells, current pulses that produced $\sim 30-40 \mathrm{mV}$ 
Aa

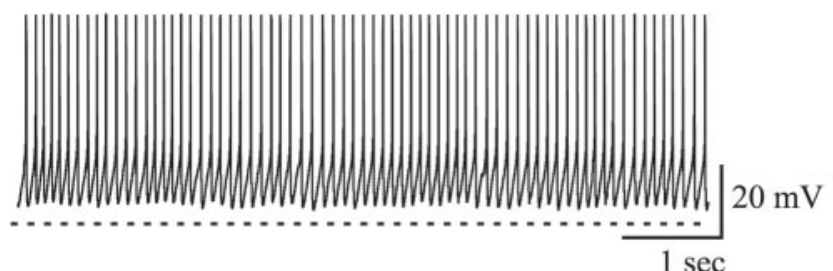

b

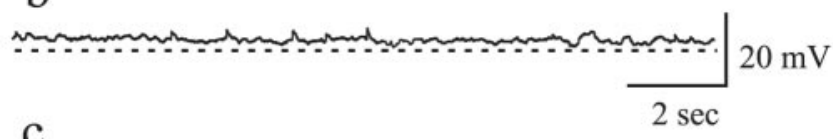

c

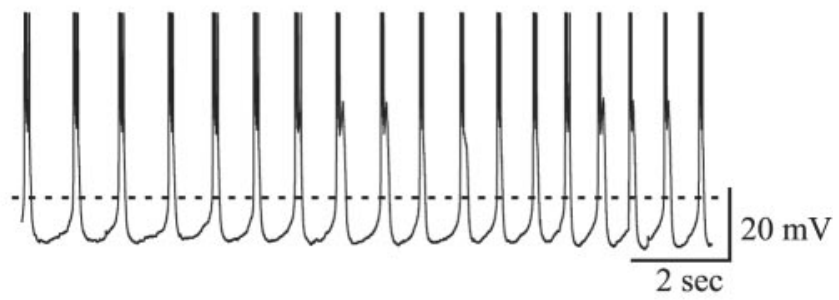

B

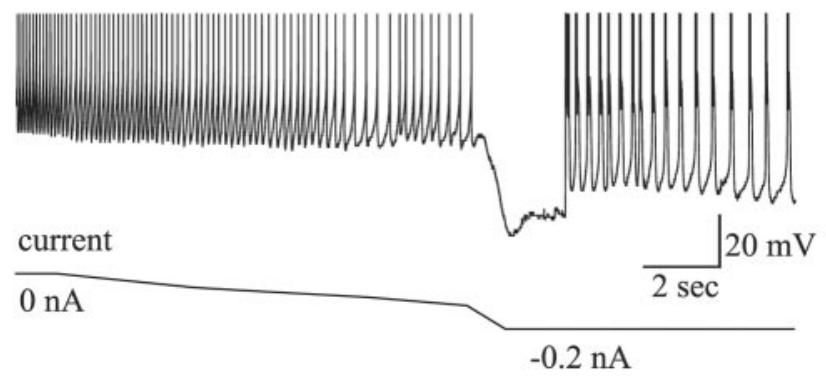

Figure 3. Three distinct patterns of spontaneous activity recorded from neurons of the medial part of the lateral habenula. $A a$, One group of cells generated tonic firing of action potentials at rest. Dotted line indicates membrane potential of $-60 \mathrm{mV}$. $A b$, Another group of cells were silent at rest. $A c$, The last group generated burst oscillations in resting conditions. $B$, A subpopulation of cells in the first group changed its spontaneous firing from tonic to burst oscillations in response to membrane hyperpolarization by a steady negative current. Action potentials are truncated.

membrane hyperpolarization were used to activate prolonged discharges of action potentials.

The activation of the long-lasting discharge of action potentials was dependent on the membrane potential of habenular cells. Whereas hyperpolarizing current pulse triggered longlasting discharges of action potentials at membrane potentials between -55 and $-65 \mathrm{mV}$, it failed to do so when the membrane potential was hyperpolarized at less than $-70 \mathrm{mV}$. At potentials less than $-70 \mathrm{mV}$, brief depolarizing current pulse (100 msec) was effective in activating the prolonged discharges (Fig. $4 \mathrm{~A}$ ).

These results suggest that the long-lasting increase in tonic firing in response to synaptic stimulation of the stria medullaris (Fig. 2) is mediated by the intrinsic properties of habenular cells that are activated in response to transient membrane hyperpolarization.

\section{A tonic entry of $\mathrm{Na}^{+}$underlies long-lasting discharges of action potentials}

To characterize the ionic mechanism that underlies the longlasting discharges of action potentials, we blocked action poten-

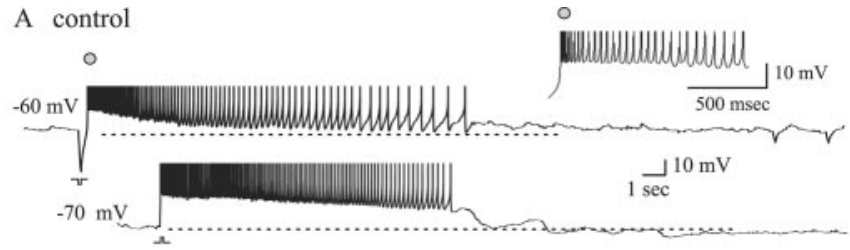

B TTX
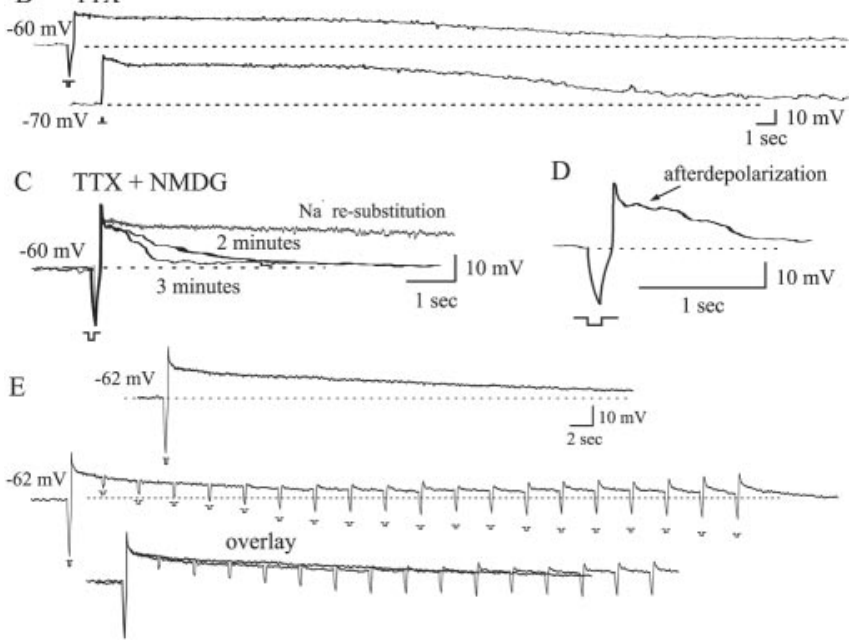

Figure 4. A brief membrane hyperpolarization induced prolonged discharges of action potentials. A, At membrane potentials of more than -65 to $-70 \mathrm{mV}$, a hyperpolarizing current pulse triggered long-lasting discharges of action potentials, whereas a depolarizing current pulse activated similar discharges at less than -70 to $-75 \mathrm{mV}$. The initial bust discharge is expanded in the inlet. The action potentials are truncated. $B$, The block of action potentials by bath infusion of $1 \mu \mathrm{m}$ TTX revealed a persistent membrane depolarization that underlay the long-lasting discharges of action potentials. C, A reduction of external $\mathrm{Na}^{+}$from 151 to $26 \mathrm{~mm}$ by the substitution of external $\mathrm{NaCl}$ with NMDG-Cl blocked most of the persistent depolarization and uncovered a transient rebound depolarization in response to a hyperpolarizing current pulse. Resubstitution of NMDG-Cl with $\mathrm{NaCl}$ restored the persistent membrane depolarization in response to current pulse injection. $D$, Expansion of the rebound depolarization recorded $3 \mathrm{~min}$ after the infusion of NMDG-Cl shown in C. The initial peak of the rebound depolarization is followed by the afterdepolarization of $\sim 1$ sec in duration. $E$, The injection of hyperpolarizing current pulses at regular intervals showed a progressive increase in cell input resistance, but had little effects on the duration of the persistent depolarization of the membrane.

tial generation in an attempt to uncover any persistent change in the membrane potential that is associated with the prolonged generation of action potentials. In 12 cells analyzed, after bath infusion of $0.5-1 \mu \mathrm{M}$ TTX, a hyperpolarizing current pulse (100 $\mathrm{msec}$ ) at membrane potentials of more than $-65 \mathrm{mV}$ resulted in a persistent depolarization of the membrane in duration ranging from 5.2 to $55.7 \mathrm{sec}$. The average duration from the 12 cells was $19.6 \pm 16.2 \mathrm{sec}$. One example of such cases is shown in Figure 4, $A$ and $B$. In this cell, the injection of a hyperpolarizing current pulse in the presence of TTX activated a rebound depolarization, the peak of which reached the membrane potential of -20 to $-30 \mathrm{mV}$ immediately after the break of current pulse (Fig. $4 B$ ). The membrane potential then remained depolarized and steady for the initial 18-20 sec before gradually declining to baseline over the next $20 \mathrm{sec}$. At potentials less than $-70 \mathrm{mV}$, a brief depolarizing current pulse activated a similar persistent depolarization of the membrane. These results indicate that the longlasting discharge of action potentials in response to synaptic stimulation of the stria medullaris that was shown in Figure 2 is mediated by the generation of a persistent membrane depolarization in response to a brief synaptic hyperpolarization of habenular cells.

To characterize the ionic mechanism underlying the TTX- 
insensitive, persistent membrane depolarization, we tested whether a tonic influx of $\mathrm{Na}^{+}$is involved. For this test, we lowered external $\mathrm{Na}^{+}$and examined its effect on the generation of the persistent membrane depolarization. A reduction in external $\mathrm{Na}^{+}$from 151 to $26 \mathrm{~mm}$ by replacing $\mathrm{NaCl}$ with equimolar $\mathrm{N}$-methyl-D-glucamine chloride (NMDG-Cl) eliminated most of the persistent membrane depolarization that had been produced in response to hyperpolarizing current pulse (Fig. $4 \mathrm{C}$ ). For example, in five cells tested, a hyperpolarizing current pulse in the presence of TTX and $151 \mathrm{~mm}$ external $\mathrm{Na}^{+}$generated membrane depolarization, respectively, for average duration of $7.2 \pm 2.4$, $11.3 \pm 2.7,17.7 \pm 3.2,26.3 \pm 4.0$, and $43 \pm 5.3 \mathrm{sec}$. After the reduction of external $\mathrm{Na}^{+}$to $26 \mathrm{mM}$, the same hyperpolarizing current pulse resulted in only a transient rebound depolarization in all the five cells. This transient rebound depolarization was composed of an initial rebound spike and an ensuing afterdepolarization (ADP) of $\sim 1-2 \mathrm{sec}$ in duration (Fig. 4C,D).

During the persistent membrane depolarization, we injected a small hyperpolarizing current pulse at regular intervals $(n=7$ cells) (Fig. 4D). The current pulse injection revealed a progressive increase in cell input resistance over time during the persistent membrane depolarization, indicating that the decay of the persistent depolarization is associated with a decrease in membrane conductance. The current injection, however, did not halt the persistent membrane depolarization, suggesting that the TTX-insensitive, persistent depolarization is not generated by such regenerative potentials as plateau potentials that can be repolarized abruptly by opposing hyperpolarizing influences. We refer to the underlying depolarizing potential of the TTXinsensitive, persistent depolarization of habenular cells as a "long-lasting depolarizing afterpotential (LDAP)."

The LDAP was abolished by bath infusion of $50 \mu \mathrm{M}$ flufenamic acid (FFA). This concentration of FFA has been routinely used to block nonspecific cationic currents (Shaw et al., 1995; Partridge and Valenzuela 2000; Ghamari-Langroudi and Bourque, 2002). In six cells tested, before FFA infusion, a hyperpolarizing current pulse in the presence of TTX triggered the LDAP in duration ranging from 5 to $36 \mathrm{sec}$ (Fig. $5 A, B$ ). The bath infusion of $50 \mu \mathrm{M}$ FFA blocked the generation of the LDAP and uncovered the transient rebound depolarization that consisted of an initial spike and an ADP of $\sim 1-2$ sec in duration (Fig. 5C). These spike and ADPs were similar to those shown above with the substitution of external $\mathrm{NaCl}$ with NMDG-Cl (Fig. 4C,D).

Taken altogether, those results above from TTX application, NMDG substitution, and FFA infusion suggest that the activation of a tonic $\mathrm{Na}^{+}$influx possibly through nonselective cationic channels is critical for the generation of the LDAP in response to a brief membrane hyperpolarization.

\section{$\mathrm{Ca}^{2+}$ entry triggers the generation of the LDAP}

The generation of the transient rebound spike in response to a hyperpolarizing current pulse that was uncovered by NMDG substitution or bath infusion of FFA resembles that of the $\mathrm{Ca}^{2+}$ spike through the activation of low-threshold T-type $\mathrm{Ca}^{2+}$ channels, as was shown in numerous areas of the brain (Llinas and Yarom, 1981; Jahnsen and Llinas, 1984a,b; Llinas and Muhlethaler, 1988; Huguenard, 1996). In fact, a previous study demonstrated the presence of T-type $\mathrm{Ca}^{2+}$ current in rat lateral habenular cells (Wilcox et al., 1988; Huguenard et al., 1993).

The generation of the transient spike and the ADP that appear to precede and underlie, respectively, the LDAP raises the question of whether $\mathrm{Ca}^{2+}$ entry during the transient rebound depolarization plays a role in the activation of the persistent mem-
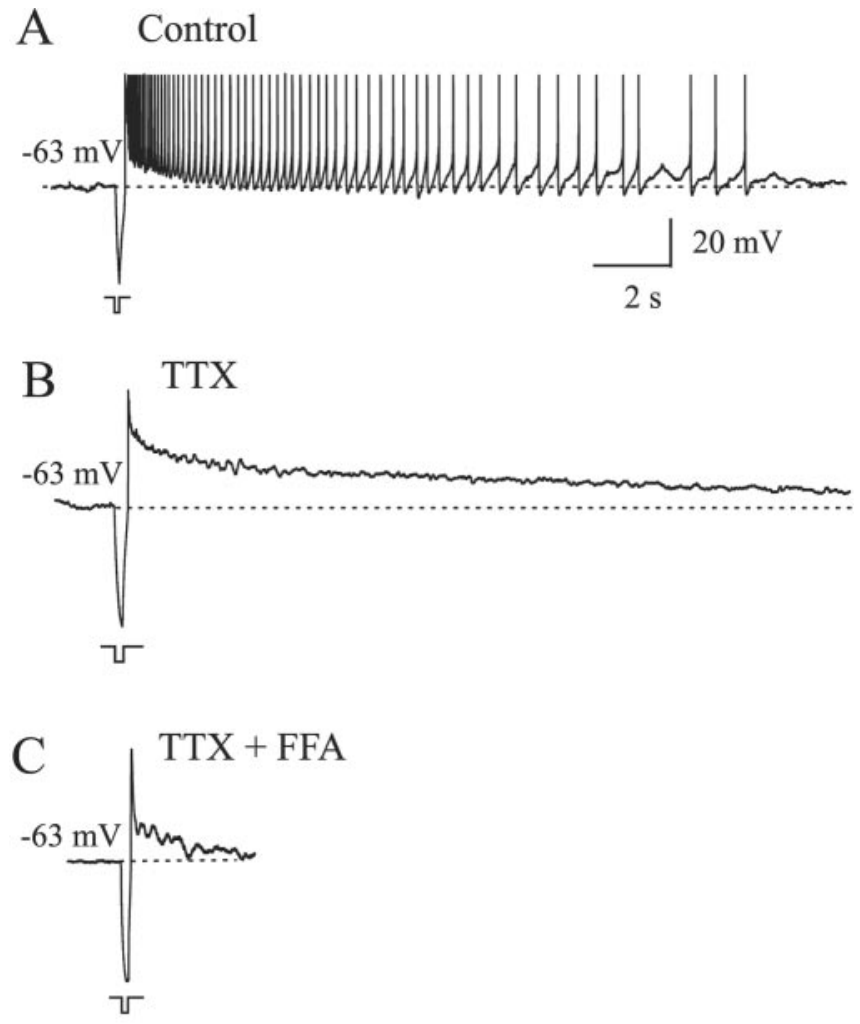

\section{FFA washout}

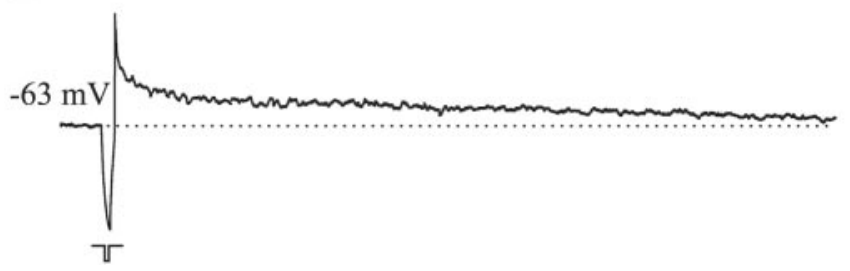

Figure 5. Flufenamic acid blocks the generation of the LDAP. $A$, A hyperpolarizing current pulse induced persistent discharges of action potentials. $B$, Bath infusion of $1 \mu \mathrm{m}$ TTX revealed the LDAP underlying the persistent discharges of action potentials. $C$, The subsequent bath infusion of $50 \mu \mathrm{mFFA}$ blocked the LDAP and uncovered a transient spike and the ensuing ADP in response to current pulse injections. D, The LDAP was regenerated after FFA washout.

brane depolarization. To address this question, we removed $\mathrm{Ca}^{2+}$ from the external solution and examined its effect on the LDAP. A representative case is shown in Figure 6. This cell was spontaneously active and continued to generate action potentials at $\sim 5-6 \mathrm{~Hz}$ (Fig. $6 \mathrm{~A}$ ). The injection of a hyperpolarizing current pulse at membrane potentials more than $-65 \mathrm{mV}$ resulted in long-lasting discharges of action potentials for $\sim 15-20 \mathrm{sec}$. After bath infusion of $1 \mu \mathrm{M}$ TTX, the hyperpolarizing current pulse generated the LDAP of $30-35 \mathrm{sec}$ in duration. In this cell, the removal of external $\mathrm{Ca}^{2+}$ eliminated not only the transient spike and ADP but also the LDAP in response to either a hyperpolarizing or depolarizing current pulse (Fig. $6 B)(n=8$ cells). This result indicates, first, that the transient rebound spike and ADP are generated by $\mathrm{Ca}^{2+}$ entry and, second, that they are important for the subsequent activation of the LDAP.

To determine whether it is $\mathrm{Ca}^{2+}$ entry or the change in the membrane voltage during the transient rebound depolarization that induces the LDAP, we generated a voltage command that simulated the temporal change in the membrane voltage that was observed during the rebound generation of the transient spike in 
A control

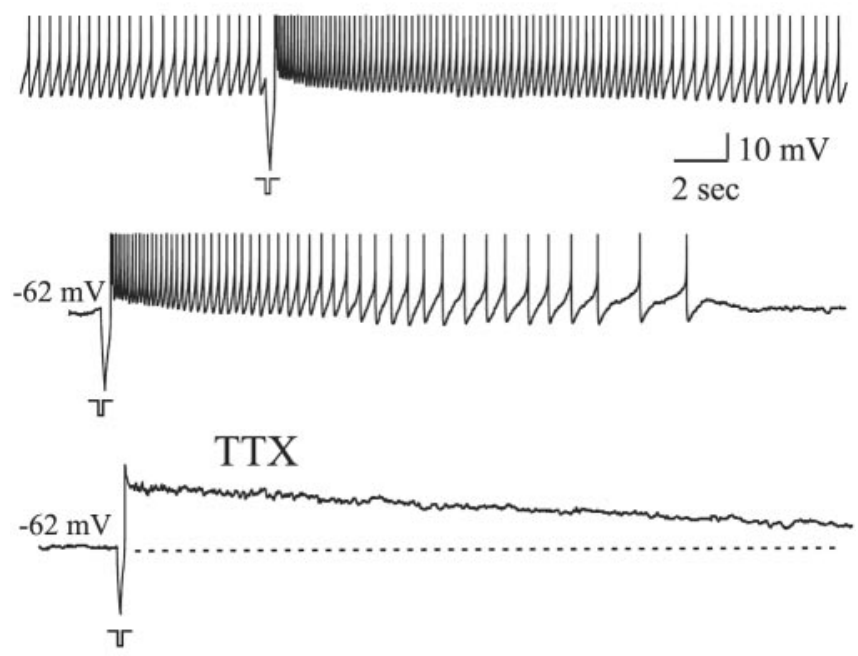

B $0 \mathrm{mM} \mathrm{Ca}^{2 *}$

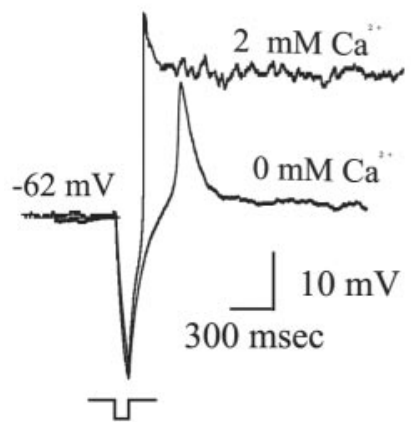

C

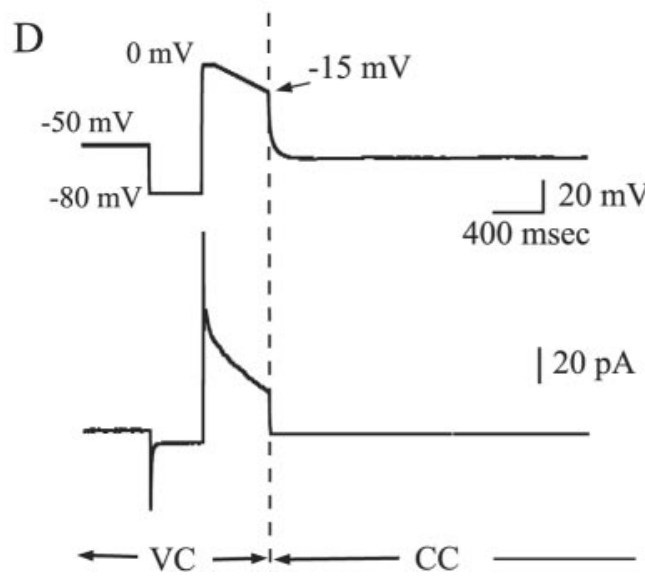

Figure 6. $\mathrm{Ca}^{2+}$ entry during the transient spike is crucial for the induction of the LDAP. A, The injection of a hyperpolarizing current pulse at rest increased spontaneous firing of action potentials. At $-62 \mathrm{mV}$, the hyperpolarizing current pulse triggered prolonged discharges of action potentials. The block of action potentials by $1 \mu \mathrm{m}$ TTX revealed the LDAP. B, At $20-30 \mathrm{sec}$ after bath infusion of $0 \mathrm{~mm}$ external $\mathrm{Ca}^{2+}$, the LDAP was eliminated. Only a prominent transient rebound spike was generated. C, At 3-5 min after bath infusion of $0 \mathrm{~mm}$ external $\mathrm{Ca}^{2+}$, the transient spike was also blocked. $D$, In $0 \mathrm{~mm}$ external $\mathrm{Ca}^{2+}$, the simulation under voltage-clamp conditions (VC) of the rebound depolarization failed to induce the LDAP when the recording was switched to current-clamp mode (CC) when the simulated rebound spike declined to $-15 \mathrm{mV}$ past the peak (top). The bottom is the current recorded during the simulation of the rebound depolarization under voltage-clamp conditions (VC) and after switching the amplifier to current-clamp mode (CC).

\section{Intracellular $10 \mathrm{mM}$ BAPTA}
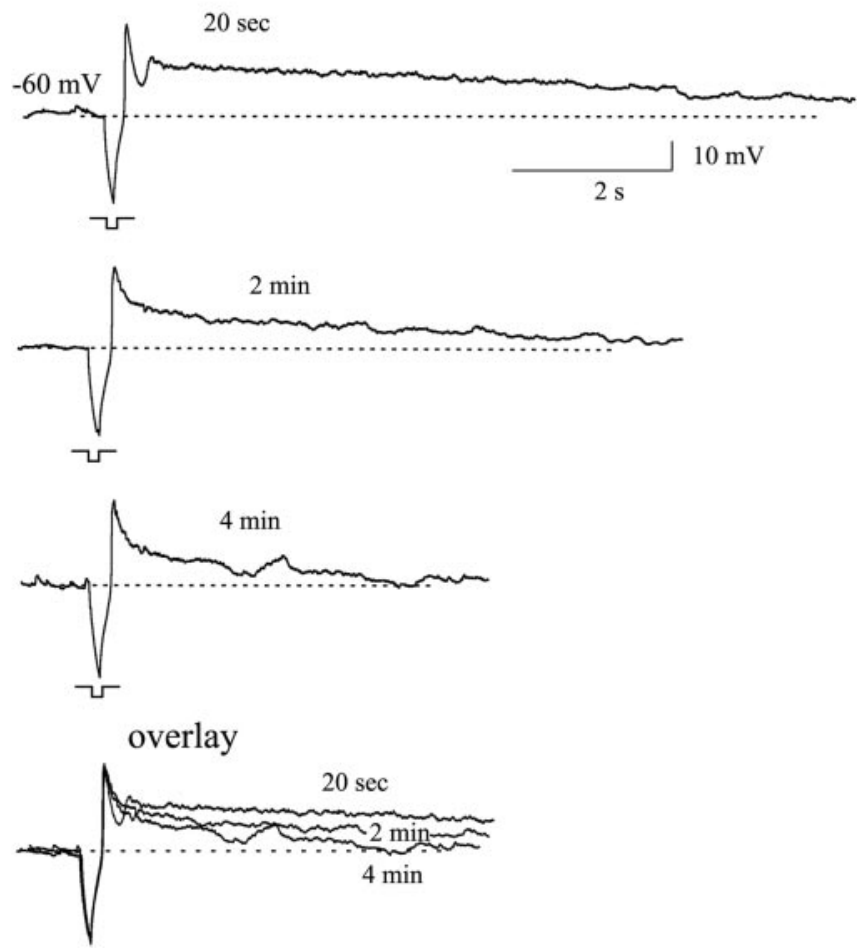

Figure 7. Intracellular infusion of $10 \mathrm{~mm}$ BAPTA gradually blocks the activation of the LDAP. After 4 min of BAPTA infusion, a hyperpolarizing current pulse generated a rebound depolarization of $2-3 \mathrm{sec}$. The external solution contained $0.5 \mu \mathrm{m} \mathrm{TTX.}$

response to a hyperpolarizing current pulse (Fig. 6D). We applied the voltage command to seven different habenular cells in 0 mM external $\mathrm{Ca}^{2+}$ to examine whether the simulated membranerebound depolarization that mimics the generation of the transient spike would elicit the LDAP in the absence of external $\mathrm{Ca}^{2+}$. In the presence of $2 \mathrm{mM}$ external $\mathrm{Ca}^{2+}$, those seven cells tested generated the LDAP in duration ranging from 7 to $35 \mathrm{sec}$ in response to a hyperpolarizing current pulse. Then, after external $\mathrm{Ca}^{2+}$ was lowered to $0 \mathrm{~mm}$, the cells were held at $-50 \mathrm{mV}$ under voltage-clamp conditions, and the voltage command was delivered. When the simulated rebound depolarization proceeded past the peak at $0 \mathrm{mV}$ and declined to $-15 \mathrm{mV}$, the intracellular amplifier was swiftly switched to the current-clamp recording mode to examine whether the simulated rebound depolarization triggered the LDAP. In $0 \mathrm{~mm}$ external $\mathrm{Ca}^{2+}$, after switching the amplifier to the current-clamp mode, the membrane potential immediately declined to baseline, indicating that $\mathrm{Ca}^{2+}$ entry into the cell, not the change in membrane voltage, during the rebound transient spike is critical for the activation of the LDAP. In addition, in the absence of external $\mathrm{Ca}^{2+}$, when the habenular cells were hyperpolarized at less than $-70 \mathrm{mV}$ by steady negative current, the injection of a depolarizing current pulse $(0.1-1 \mathrm{sec})$ that depolarized the cells to $-20-0 \mathrm{mV}$ also failed to elicit the LDAP (Fig. 6C).

The chelation of intracellular $\mathrm{Ca}^{2+}$ by including $10 \mathrm{~mm}$ bis (2aminophenoxy)ethane- $N, N, N^{\prime}, N^{\prime}$-tetra-acetic acid (BAPTA) in the pipette solution also resulted in a progressive decrease in the amplitude and duration of the LDAP with time in response to hyperpolarizing current pulse (Fig. 7) ( $n=6$ cells). After 4 min, the injection of a hyperpolarizing current pulse elicited a similar transient rebound depolarization that was composed of an initial 

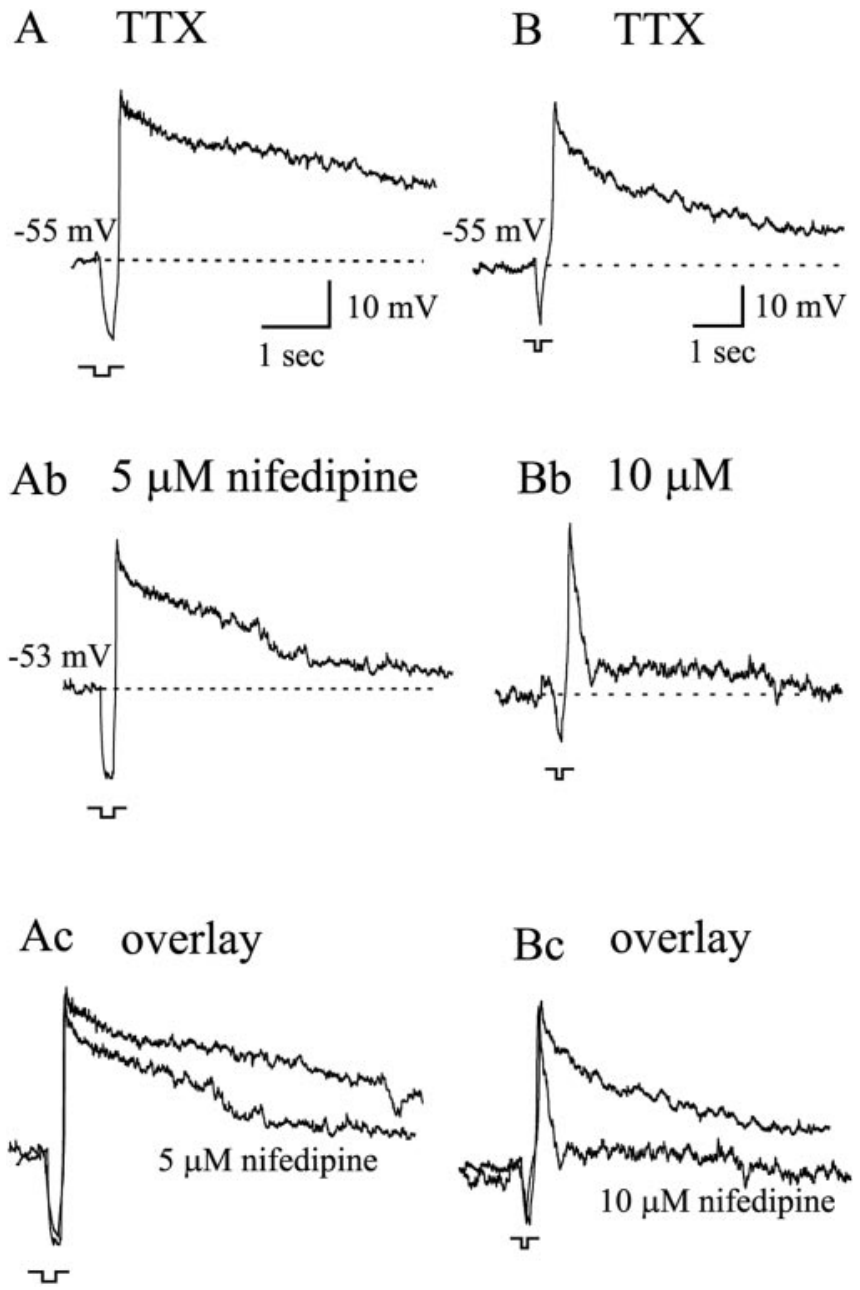

Figure 8. The block of $\mathrm{Ca}^{2+}$ entry though L-type $\mathrm{Ca}^{2+}$ channels decreases the duration of the LDAP. A, Bath infusion of $5 \mu \mathrm{m}$ nifedipine reduced the duration of the LDAP by $65 \pm 12 \%$. $B$, A higher concentration of nifedipine (10-15 $\mu \mathrm{m})$ blocked the LDAP and uncovered a transient rebound spike in response to current pulse injection. Nifedipine effect did not wash out after re-infusion of ACSF for $20 \mathrm{~min}$.

spike and ensuing ADP as was shown with NMDG substitution and bath infusion of FFA (Figs. $4 C, D, 5 C$ ). This result also supports that $\mathrm{Ca}^{2+}$ entry is critical for the activation of the LDAP.

Taken altogether, the results shown so far suggest that $\mathrm{Ca}^{2+}$ entry during the transient rebound depolarization triggers the activation of a tonic influx of $\mathrm{Na}^{+}$. This tonic influx of $\mathrm{Na}^{+}$ drives the long-lasting depolarization of habenular cells that promotes persistent discharges of action potentials.

$\mathrm{Ca}^{2+}$ entry through L-type $\mathrm{Ca}^{2+}$ channels triggers the LDAP $\mathrm{Ca}^{2+}$ entry through T-type $\mathrm{Ca}^{2+}$ channels produces the transient spike in the habenular cells. During the generation of the transient spike, $\mathrm{Ca}^{2+}$ is also likely to enter the cell through highthreshold $\mathrm{Ca}^{2+}$ channels when the membrane potential depolarizes at more than $-30 \mathrm{mV}$. In particular, the ADP ensuing the initial spike during rebound depolarization could be mediated by $\mathrm{Ca}^{2+}$ entry through high-threshold $\mathrm{Ca}^{2+}$ channels.

To determine which $\mathrm{Ca}^{2+}$ entry leads to the activation of the LDAP, we blocked L-type $\mathrm{Ca}^{2+}$ channels by bath infusion of nifedipine in a total of 10 cells. In one half of the 10 cells, we applied $5 \mu \mathrm{M}$ nifedipine in the bathing medium. In the other half,
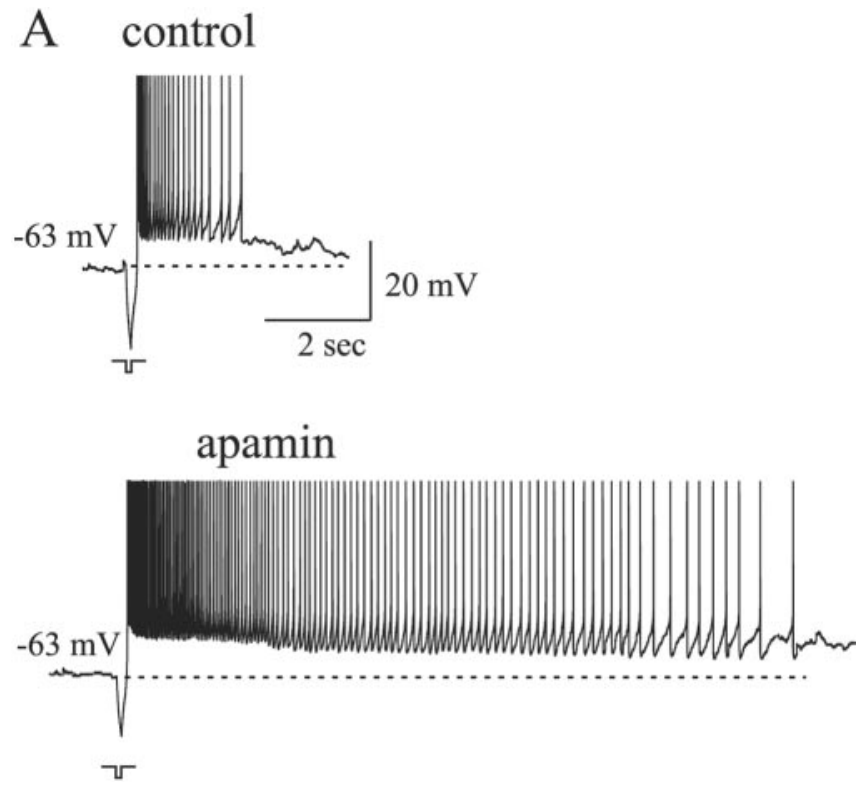

Figure 9. A, Bath infusion of $100 \mathrm{~nm}$ apamin increased the duration of action potential generation in response to a hyperpolarizing current pulse. The effect of apamin did not wash out after re-infusion of ACSF for $20 \mathrm{~min}$.

we increased nifedipine to $10-15 \mu \mathrm{M}$. The bath infusion of $5 \mu \mathrm{M}$ nifedipine decreased the duration of the LDAP by $65.1 \pm 11.8 \%$ $(p<0.05)$ (Fig. 8A). In those five cells, $5 \mu \mathrm{M}$ nifedipine shortened the duration of the LDAP on average from 9.7 to 3.9, 10.1 to $5.3,14.3$ to $3.2,16.8$ to 4.7 , and 17.2 to $5.4 \mathrm{sec}$, respectively, when generated in response to hyperpolarizing current pulse. In the other five cells, bath infusion of 10-15 $\mu \mathrm{M}$ nifedipine blocked most of the LDAP (Fig. $8 B$ ). In these cells, before nifedipine infusion, a hyperpolarizing current pulse generated the LDAP in average durations of $7.2,15.0,18.2,18.7$, and $22.3 \mathrm{sec}$, respectively. After bath infusion of nifedipine, the hyperpolarizing current pulse generated a transient spike without the ADP. These results indicate, first, that $\mathrm{Ca}^{2+}$ entry through $\mathrm{L}$-type $\mathrm{Ca}^{2+}$ channels plays a dominant role in the activation of the LDAP and, second, that the ADP is mediated mostly by activation of L-type $\mathrm{Ca}^{2+}$ channels.

\section{The activation of $\mathrm{K}^{+}$currents plays a role in terminating the LDAP}

The block of action potentials by TTX disclosed the LDAP that was often longer than the duration of the promoted discharge of action potentials in response to current pulse injection (Figs. 4-6). One possible explanation for this phenomenon is that the action potential generation results in the activation of various $\mathrm{K}^{+}$ currents, and these outward $\mathrm{K}^{+}$currents exert an influence toward the termination of the LDAP.

To verify the role of $\mathrm{K}^{+}$currents in the termination of the LDAP, we selected one particular type of $\mathrm{K}^{+}$current, the $\mathrm{Ca}^{2+}$ activated $\mathrm{K}^{+}$current. We examined how the block of the $\mathrm{Ca}^{2+}$ activated $\mathrm{K}^{+}$current influences the LDAP. The bath infusion of $100 \mathrm{nM}$ apamin, the specific blocker of small conductance $\mathrm{Ca}^{2+}$ activated $\mathrm{K}^{+}$current, resulted in the prolongation of the LDAP by $285 \pm 110 \%(p<0.01)$ (Fig. 9). In four cells tested, apamin increased the average durations of the LDAP from 4.5 to 20.2, 13.7 to $32.3,22.8$ to 47.6 , and 40.3 to $109.4 \mathrm{sec}$, respectively. 


\section{Dual role of intracellular $\mathrm{Ca}^{2+}$ mobilization by the ER in the generation of the LDAP}

The sensitivity of the LDAP to $\mathrm{Ca}^{2+}$ entry raises the possibility that intracellular $\mathrm{Ca}^{2+}$ regulation may also play an important role in controlling the duration of the persistent discharge of action potentials induced by synaptic hyperpolarization. In neurons, the endoplasmic reticulum (ER) is considered to be the major organelle that regulates intracellular $\mathrm{Ca}^{2+}$ concentration in physiological conditions (Svoboda and Mainen, 1999; Berridge et al., 2000; Rose and Konnerth, 2001). On the one hand, in response to either signaling stimuli or $\mathrm{Ca}^{2+}$ entry from the external space, the ER releases $\mathrm{Ca}^{2+}$ into the cytoplasm and increases intracellular $\mathrm{Ca}^{2+}$ levels. On the other hand, the ER takes up $\mathrm{Ca}^{2+}$ from the cytoplasm for cell homeostasis and maintains a low intracellular $\mathrm{Ca}^{2+}$ concentration.

To examine the role of intracellular $\mathrm{Ca}^{2+}$ regulation by the ER in the generation of the LDAP, we first examined the possibility that $\mathrm{Ca}^{2+}$ entry from the external space induces $\mathrm{Ca}^{2+}$ release from the ER and thereby enhances the activation of the LDAP. The bath infusion of 70-100 $\mu \mathrm{M}$ dantrolene, the blocker of $\mathrm{Ca}^{2+}$ release from the ER (Fruen et al., 1997; Zhao et al., 2001), significantly decreased the duration of the LDAP by $68.3 \pm 12.5 \%$ $(p<0.01)(n=5$ of five cells tested) (Fig. 10A). In those four cells tested, $10 \mathrm{~min}$ after dantrolene infusion, the average duration of the LDAP was decreased from 13.6 to $4.9,18.0$ to $9.0,19.2$ to $5.9,24.7$ to 6.2 , and 29.4 to $4.9 \mathrm{sec}$, respectively.

In contrast, the block of $\mathrm{Ca}^{2+}$ uptake into the ER by bath infusion of $1 \mu \mathrm{M}$ thapsigargin resulted in a prolongation of the LDAP by $315 \pm 263 \%(p<0.01)$ in five of five cells tested. It has been shown that this concentration of thapsigargin blocks $\mathrm{Ca}^{2+}$ uptake into the ER (Thastrup et al., 1990; Treiman et al., 1998). In those cells tested, $1 \mu \mathrm{M}$ thapsigargin increased the average duration of the LDAP from 3.4 to $7.2,7.5$ to $15.4,20.2$ to $49.1,39.3$ to 82.2 , and 55.2 to $95.6 \mathrm{sec}$, respectively (Fig. $10 \mathrm{~B}$ ).

These results suggest that intracellular $\mathrm{Ca}^{2+}$ mobilization by the ER plays two different roles depending on the stage of the development of the LDAP. At early stages, the induction of $\mathrm{Ca}^{2+}$ release from the ER enhances the generation of the LDAP, whereas, at later stages, the uptake of $\mathrm{Ca}^{2+}$ into the ER decreases contributes to its termination.

\section{Discussion}

In this study, we characterized the ionic mechanism through which hyperpolarizing postsynaptic potentials induce longlasting discharges of tonic action potentials

The electrical stimulation of synaptic input from the limbic forebrain to the habenula produces a synaptic hyperpolarization of cells in the medial part of the lateral habenular nucleus. We demonstrated that the brief membrane hyperpolarization triggers a series of cellular events that lead to the activation of an LDAP that stimulates prolonged discharges of action potentials.

\section{$\mathrm{Ca}^{2+}$ entry from the external space triggers the generation of the LDAP}

$\mathrm{Ca}^{2+}$ entry through T- and L-type $\mathrm{Ca}^{2+}$ channels plays distinct roles in the activation of the LDAP. A brief hyperpolarization of habenular cells triggers the rebound generation of a transient spike that is mediated by $\mathrm{Ca}^{2+}$ entry through $\mathrm{T}$-type $\mathrm{Ca}^{2+}$ channels. The depolarization of the membrane by the transient spike in turn results in the activation of high threshold $\mathrm{Ca}^{2+}$ channels. $\mathrm{Ca}^{2+}$ entry through L-type high-threshold $\mathrm{Ca}^{2+}$ channels then leads to the activation of a tonic influx of $\mathrm{Na}^{+}$that generates an

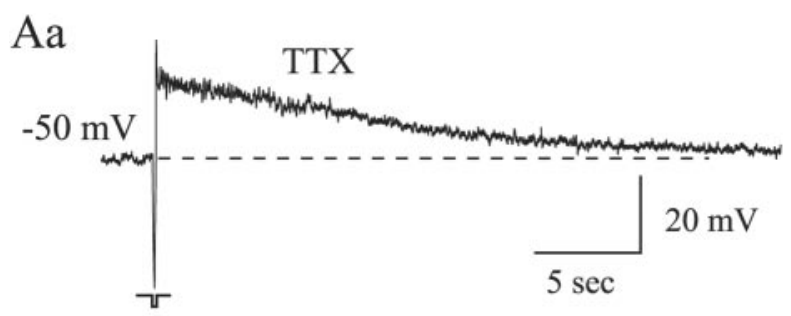

\section{$\mathrm{Ab} \quad \mathrm{TTX}+$ Thapsigargin}
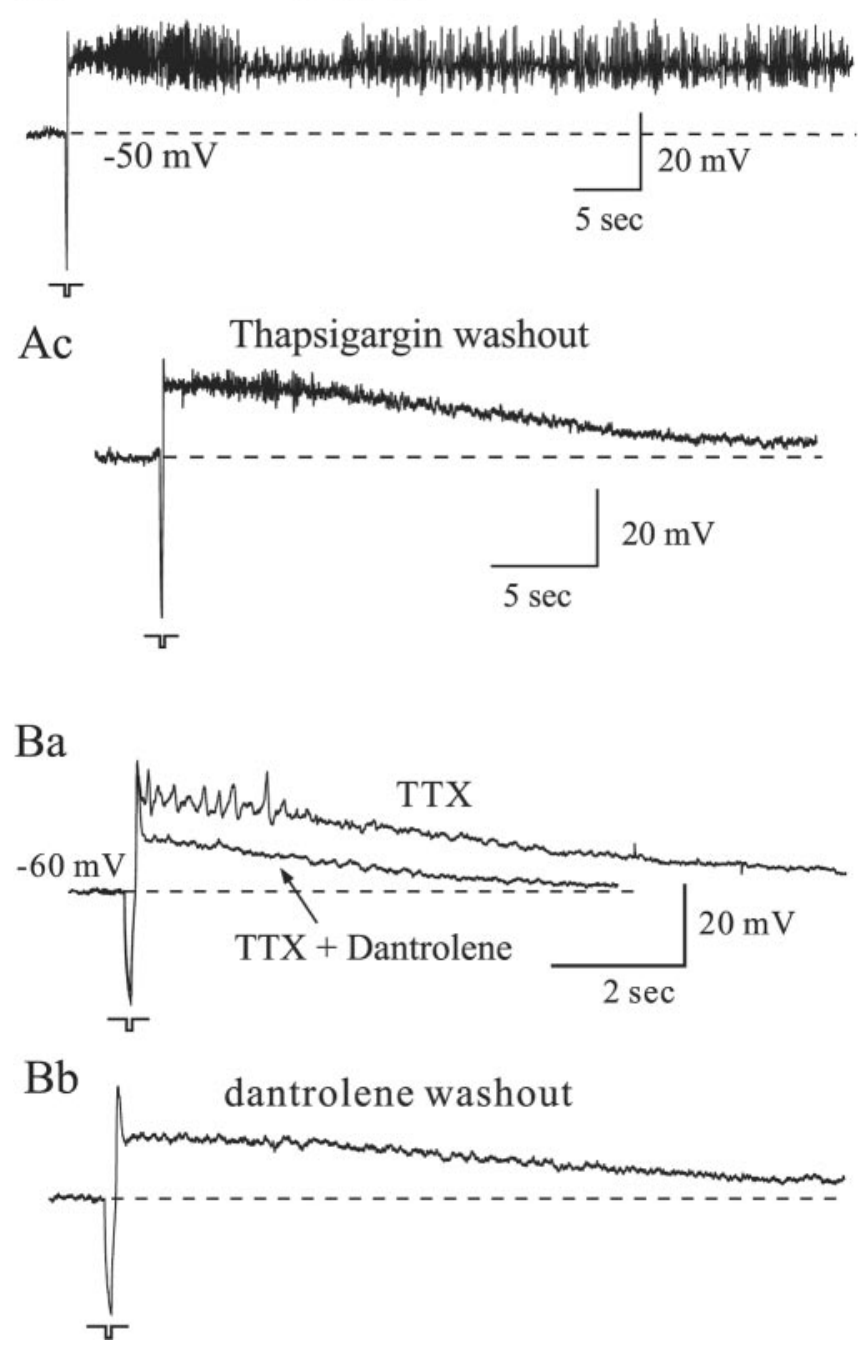

Figure 10. The release of $\mathrm{Ca}^{2+}$ from the ER enhances the generation of the LDAP, whereas the block of $\mathrm{Ca}^{2+}$ release from the ER prolongs it. $A$, The block of $\mathrm{Ca}^{2+}$ uptake into the ER by bath infusion of $1 \mu \mathrm{m}$ thapsigargin prolongs the duration of the LDAP. Note the change in time scale in $A b . B$, The block of $\mathrm{Ca}^{2+}$ release from the ER by bath infusion of 70-100 $\mu$ m dantrolene significantly decreases the amplitude and duration of the LDAP.

LDAP. The persistent depolarization driven by the LDAP stimulates prolonged, intense discharges of tonic action potentials.

We propose that the LDAP is most likely mediated through the activation of CAN currents for the following reasons. First, the substitution of external $\mathrm{Na}^{+}$with $\mathrm{NMDG}^{+}$abolished the LDAP, indicating that the LDAP is generated by a tonic entry of $\mathrm{Na}^{+}$. Second, the LDAP is not blocked by TTX, indicating that the tonic $\mathrm{Na}^{+}$entry is not mediated through voltage-gated $\mathrm{Na}^{+}$ channels. Third, the LDAP is triggered by $\mathrm{Ca}^{2+}$ entry into the cell. Fourth, the LDAP is blocked by low concentrations of FFA that have been routinely used to block nonselective cationic cur- 
rents. These characteristics of the LDAP are consistent with those of the depolarizing potentials that were reported to be generated by $\mathrm{Ca}^{2+}$-activated nonselective cationic (CAN) currents (Partridge and Swandulla, 1993; Wilson et al., 1996; Morisset and Nagy, 1999; Partridge and Valenzuela, 1999, 2000). Although we still cannot rule out the possibility that the LDAP of habenular cells is generated by some other currents yet to be characterized, it is most likely that it is generated by CAN currents.

Whereas $\mathrm{Ca}^{2+}$ entry through T-type channels is indispensable for the activation of the LDAP as it generates a rebound spike in response to synaptic hyperpolarization and thereby activates L-type $\mathrm{Ca}^{2+}$ channels, $\mathrm{Ca}^{2+}$ entry through T-type channels alone appears to be insufficient to activate the LDAP. In our results, the block of L-type $\mathrm{Ca}^{2+}$ channels by bath infusion of 10-15 $\mu \mathrm{M}$ nifedipine significantly blocked the LDAP while uncovering the rebound spike that is presumably mediated by T-type $\mathrm{Ca}^{2+}$ currents. This result indicates that $\mathrm{Ca}^{2+}$ entry through L-type channels is critical for the activation of the LDAP. It is not clear why $\mathrm{Ca}^{2+}$ entry through T-type channels alone is insufficient for the activation of the LDAP. Possibly, the subcellular distribution of T-type $\mathrm{Ca}^{2+}$ channels is different from that of those channels mediating a tonic entry of $\mathrm{Na}^{+}$for generation of the LDAP, or $\mathrm{Ca}^{2+}$ conductance through T-type channels is not large enough to increase local $\mathrm{Ca}^{2+}$ levels above the threshold concentration for the activation of the channels mediating the tonic entry of $\mathrm{Na}^{+}$.

Another intriguing difference between L- and T- type $\mathrm{Ca}^{2+}$ channels is that $\mathrm{Ca}^{2+}$ entry through L-type channels induces $\mathrm{Ca}^{2+}$ release from the ER. This $\mathrm{Ca}^{2+}$-induced $\mathrm{Ca}^{2+}$ release from the ER amplifies the generation of the LDAP. Indeed, the block of $\mathrm{Ca}^{2+}$ release from the ER by dantrolene markedly reduced the duration of the LDAP by $68 \pm 13 \%$ (Fig. 10B). Based on these results, it seems reasonable to propose that $\mathrm{Ca}^{2+}$ entry through L-type channels results in the activation of the LDAP to a larger extent via inducing $\mathrm{Ca}^{2+}$ release from the ER than through the direct activation of the $\mathrm{Ca}^{2+}$-activated tonic $\mathrm{Na}^{+}$entry.

\section{The maintenance and termination of the LDAP}

The duration of the LDAP appears to be determined by the sum of opposing depolarizing and hyperpolarizing influences that change in their relative strength during the time course of the depolarizing potential generation. The major current that activates and sustains the LDAP is a tonic influx of $\mathrm{Na}^{+}$ions probably through CAN channels.

At lease two cellular systems work together toward the termination of the LDAP. One is the activation of outward $\mathrm{K}^{+}$currents. In particular, we showed that $\mathrm{Ca}^{2+}$ entry into the cytoplasm increases the activation of $\mathrm{K}^{+}$currents that oppose the persistent membrane depolarization. In our experiments, the block of small conductance $\mathrm{Ca}^{2+}$-activated $\mathrm{K}^{+}$currents by apamin resulted in the prolongation of the LDAP. This result indicates a dual, contrasting action of $\mathrm{Ca}^{2+}$ entry in the generation of the LDAP. At early stages of its generation, the dominant action of $\mathrm{Ca}^{2+}$ is to trigger and sustain the LDAP probably through the activation of CAN currents. At later stages, the relative influence of $\mathrm{Ca}^{2+}$ on the activation of $\mathrm{K}^{+}$currents increases and thereby contributes to the termination of the LDAP. Although not examined in this study, the activation of other types of $\mathrm{K}^{+}$currents is also likely involved in the termination of the LDAP.

The other cellular component that contributes to the termination of the LDAP is $\mathrm{Ca}^{2+}$ uptake by the ER. This action of the $\mathrm{ER}$ is contrasted with its contribution to the generation and en- hancement of the LDAP at early stages when the ER releases $\mathrm{Ca}^{2+}$ into the cytoplasm in response to $\mathrm{Ca}^{2+}$ entry from the external space. Based on our observation that the block of $\mathrm{Ca}^{2+}$ uptake into the ER by thapsigargin markedly prolonged the LDAP (Fig. $10 \mathrm{~A}$ ), we propose that at later stages, the uptake of $\mathrm{Ca}^{2+}$ into the ER lowers intracellular $\mathrm{Ca}^{2+}$ levels and thus expedites the termination of the $\mathrm{Ca}^{2+}$-activated tonic $\mathrm{Na}^{+}$entry.

\section{Functional significance of the long-lasting depolarization of habenular cells}

As described in the Introduction, based on anatomical circuitry, the habenula is generally divided into three parts: medial nucleus, medial part of the lateral nucleus, and lateral part of the lateral nucleus (Herkenham and Nauta, 1977, 1979; Sutherland, 1982; Ellison, 1994; but see Andres at al, 1999; Geisler et al., 2003).

The present study and other previous studies showed that the three areas of the habenula exhibit different electrical properties. In our recordings, most neurons in the medial nucleus of the habenula generate tonic series of spontaneous action potentials, whereas cells in the lateral part of the lateral habenula mostly generate burst discharges of action potentials (data not shown). These patterns of electrical activity are consistent with those reported in previous studies (McCormick and Prince, 1987; Wilcox et al., 1988; Huguenard et al., 1993). The medial part of the lateral habenula contains both types of neurons that generate action potentials in tonic and burst modes. More distinctively, the major population of neurons in this area generates prolonged discharges of action potentials in response to a brief membrane hyperpolarization. Those neurons with such distinct pattern of action potential generation are densely populated in particular near the border to the medial habenular nucleus.

The previous anatomical studies showed that the medial part of the lateral habenula, while receiving input from the limbic regions of the forebrain, gives rise to projections to various areas of the hypothalamus, substantia nigra pars compacta, ventral tegmental area, dorsal raphe nucleus, etc. In agreement with the anatomical circuitry, the electrical activity of the habenula has been shown to exert a powerful control over the activity of serotonin cells in the nucleus of dorsal raphe and dopamine cells in the ventral tegmental area and substantia nigra (Matsuda and Fujimura, 1992; Ferraro et al., 1996; Morris et al., 1999; Conley et al., 2002).

What would be the possible advantage of the striatum and limbic forebrain to exert influences on the midbrain structures via the medial part of the lateral habenula? Although we have not yet characterized the neurotransmitter type of the synaptic afferents from the striatum and limbic forebrain, the major effect of synaptic activation of these afferents appears to be a transient hyperpolarization of cells in the medial part of the lateral habenula. The intrinsic property of the habenular cells that produces long-lasting discharges in response to transient synaptic hyperpolarization may render the medial part of the lateral habenula to function as an interface that converts inhibitory influences of the striatum and limbic forebrain into excitatory ones and conveys these excitatory influences to the midbrain. There is evidence that lateral habenular cells that project to the midbrain use excitatory amino acids as neurotransmitter (Kalen et al., 1985, 1986). The habenula may also convert a transient increase in the activity of the striatum and limbic forebrain into a persistent drive that prolongs action potential generation in downstream midbrain target neurons. Such long-lasting discharge of action potentials induced by a brief synaptic hyperpolarization may increase the 
versatility of inhibitory synapses in the regulation of neural activity.

\section{References}

Andres KH, Von During M, Veh RW (1999) Subnuclear organization of the rat habenular complexes. J Comp Neurol 407:130-150.

Berridge MJ, Lipp P, Bootman MD (2000) The versatility and universality of calcium signaling. Nat Rev Mol Cell Biol 1:11-21.

Conley RK, Cumberbatch MJ, Mason GS, Williamson DJ, Harrison T, Locker K, Swain C, Maubach K, O’Donnell R, Rigby M, Hewson L, Smith D, Rupniak NM (2002) Substance P (neurokinin 1) receptor antagonists enhance dorsal raphe neuronal activity. J Neurosci 22:7730-7736.

Ellison G (1994) Stimulant-induced psychosis, the dopamine theory of schizophrenia and the habenula. Brain Res Rev 19:223-239.

Ferraro G, Montalbano ME, Sardo P, Grutta VL (1996) Lateral habenular influence on dorsal raphe neurons. Brain Res Bull 41: 47-52.

Fruen BR, Mickelson JR, Louis CF (1997) Dantrolene inhibition of sarcoplasmic reticulum $\mathrm{Ca}^{2+}$ release by direct and specific action at skeletal muscle ryanodine receptors. J Biol Chem 272:26965-26971.

Geisler S, Andres KH, Veh RW (2003) Morphologic and cytochemical criteria for the identification and delineation of individual subnuclei within the lateral habenular complex of the rat. J Comp Neurol 458:78-97.

Ghamari-langroudi M, Bourque CW (2002) Flufenamic acid blocks depolarizing afterpotentials and phasic firing in rat supraoptic neurons. J Physiol (Lond) 545 2:537-542.

Herkenham M, Nauta WJ (1977) Afferent connections of the habenular nuclei in the rat. A horseradish peroxidase study, with a note on the fiber-of-passage problem. J Comp Neurol 173:123-146.

Herkenham M, Nauta WJ (1979) Efferent connections of the habenular nuclei in the rat. J Comp Neurol 187:19-48.

Hermann DM, Luppi P-H, Peyron C, Hinckel P, Jouvet M (1997) Afferent projections to the rat nuclei magnus, raphe pallidus and reticularis gigantocellularis pars $\alpha$ demonstrated by iontophoretic application of choleratoxin (subunit b). J Chem Neuroanat 13:1-21.

Huguenard JR (1996) Low-threshold calcium currents in central nervous system. Annu Rev Physiol 58:329-348.

Huguenard JR, Gutnick MJ, Prince DA (1993) Transient $\mathrm{Ca}^{2+}$ currents in neurons isolated from rat lateral habenula. J Neurophysiol 70:158-166.

Jahnsen H, Llinas R (1984a) Electrophysiological properties of guinea-pig thalamic neurons in vitro study. J Physiol (Lond) 349:205-226.

Jahnsen H, Llinas R (1984b) Ionic basis for the electro-responsiveness and oscillatory proper of guinea-pig thalamic neurons in vitro. J Physiol (Lond) 349:227-247.

Kalen P, Karlson M, Wiklund (1985) Possible excitatory amino acid afferents to nucleus raphe dorsalis of the rat investigated with retrograde wheat germ agglutinin and $\mathrm{D}-\left[\mathrm{H}^{3}\right]$ aspartate tracing. Brain Res 360:285-297.

Kalen P, Pritzel M, Nieoullon A, Wiklund (1986) Further evidence for excitatory amino acid transmission in the lateral habenular projection to the rostral raphe nuclei: lesion-induced decrease of high affinity glutamate uptake. Neurosci Lett 68:35-40.

Llinas R, Muhlethaler M (1988) Electrophysiology of guinea-pig cerebellar nuclear cells in the in vitro brain stem-cerebellar preparation. J Physiol (Lond) 404:241-258.

Llinas R, Yarom Y (1981) properties and distribution of ionic conductances generating electroresponsiveness of mammalian inferior olivary neurons in vitro. J Physiol (Lond) 315:569-584.

Matsuda Y, Fujimura K (1992) Action of habenular efferents on ventral tegmental area neurons studied in vitro. Brain Res Bull 28:743-749.

McCormick DA, Prince DA (1987) Acetylcholine causes rapid nicotinic excitation in the medial habenular nucleus of guinea pig, in vitro. J Neurosci 7:742-752.

Meier CL, Herrling PL (1993) N-methyl-D-aspartate induces regular firing patterns in the cat lateral habenular in vivo. Neuroscience 52:951-959.

Morisset V, Nagy F (1999) Ionic basis for plateau potentials in deep dorsal horn neurons of the rat spinal cord. J Neurosci 19:7309-7316.

Morris JS, Smith KA, Cowen PJ, Friston KJ, Dolan RJ (1999) Covariation of activity in habenular and dorsal raphe nuclei following tryptophan depletion. NeuroImage 10:163-172.

Partridge LD, Swandulla D (1993) Control of cell function by neuronal calcium-activated nonselective (CAN) cation channels. In: Nonselective cationic channels, pp 175-183. Boston: Birkhauser Verlag.

Partridge LD, Valenzuela CF (1999) $\mathrm{Ca}^{2+}$ store-dependent potentiation of $\mathrm{Ca}^{2+}$-activated nonselective cation channels in rat hippocampal neurons in vitro. J Physiol (Lond) 521:617-627.

Partridge LD, Valenzuela CF (2000) Block of hippocampal CAN channels by flufenamate. Brain Res 867:143-148.

Rose CR, Konnerth A (2001) Stores not just for storage: intracellular calcium release and synaptic plasticity. Neuron 31:519-522.

Shaw T, Lee RJ, Partridge LD (1995) Action of diphenylamine carboxylate derivatives, a family of non-steroidal anti-inflammatory drugs, on $\left[\mathrm{Ca}^{2+}\right]_{\mathrm{i}}$ and $\mathrm{Ca}^{2+}$-activated channels in neurons. Neurosci Lett 190:121-124.

Sutherland RJ (1982) The dorsal diencephalic conduction system: A review of the anatomy and functions of the habenular complex. Neurosci Biobehav Rev 6:1-13.

Svoboda K, Mainen ZF (1999) Synaptic $\mathrm{Ca}^{2+}$ : intracellular stores spill their guts. Neuron 22:427-430.

Thastrup O, Cullen PJ, Drobak BK, Hanley MR, Dawson AP (1990) Thapsigargin, a tumor promoter, discharges intracellular $\mathrm{Ca}^{2+}$ stores by specific inhibition of the endoplasmic reticulum $\mathrm{Ca}^{2+}$-ATPase. Proc Natl Acad Sci USA 87:2466-2470.

Treiman M, Caspersen C, Christensen SB (1998) A tool coming of age: thapsigargin as an inhibitor of sarco-endoplasmic reticulum $\mathrm{Ca}^{2+}$. ATPase. Trends Pharmacol Sci 19:131-135.

Wilcox KS, Gutnick MJ, Christoph GR (1988) Electrophysiological properties of neurons in the lateral habenular nucleus: an in vitro study. J Neurophysiol 59:212-225.

Wilson GF, Richardson FC, Fisher TE, Olivera M, Kaczmarek LK (1996) Identification and characterization of a $\mathrm{Ca}^{2+}$-sensitive nonspecific cation channel underlying prolonged repetitive firing in Aplysia neurons. J Neurosci 16:3661-3671.

Zhao F, Li P, Chen SR, Louise CF, Fruen BR (2001) Dantrolene inhibition of ryanodine receptors $\mathrm{Ca}^{2+}$ release channel: molecular mechanism and isoform selectivity. J Biol Chem 276:13810-13816. 